\title{
A new photonic crystal fibre with low nonlinearity, low confinement loss and improved effective mode area
}

\author{
${ }^{1,2}$ Benhaddad M., ${ }^{1}$ Kerrour F., ${ }^{2}$ Benabbes O. and ${ }^{3}$ Saouli A. \\ ${ }^{1}$ MoDERNa, Department of Electronic University of Brother Mentouri \\ Constantine 1, Constantine, Algeria \\ ${ }^{2}$ LPMS, Department of Physics University of Brother Mentouri Constantine 1, \\ Constantine, Algeria \\ ${ }^{3}$ Department of Electronic University of Brother Mentouri Constantine 1, \\ Constantine, Algeria e-mail: mohamed.benhaddad@yahoo.fr
}

Received: 07.11.2018

\begin{abstract}
Photonic crystal fibres with large mode areas are widely employed for reducing the impairments arising from various nonlinear effects. We suggest a new design of photonic crystal fibres with large effective mode area. The fibre consists of six air-hole rings with two different structures and unequal diameters, where the air holes of the third ring are filled with the substance having high refractive index. Employing a full vectorial finite-element method, we have found that our structure exhibits a large effective mode area (up to $3575 \mu \mathrm{m}^{2}$ at the light wavelength of $1200 \mathrm{~nm}$ ) and low confinement losses (about $5.70 \times 10^{-3} \mathrm{~dB} / \mathrm{km}$ at $1550 \mathrm{~nm}$ ).
\end{abstract}

Keywords: photonic crystal fibres, finite-element method, effective mode area

UDC: 535.92

\section{Introduction}

In the recent years photonic crystal fibres (PCFs) have attracted a great deal of attention of optical community. They exhibit a wide range of useful optical properties, which are impossible to achieve using a conventional technology of optical fibres, e.g. endless single-mode operation [1], anomalous dispersion at short wavelengths of light [2] and enhanced nonlinearity [3] (see the review [4]). PCFs consist of a periodic array of air holes running along the entire fibre length. There are two main categories of PCFs. The first one embraces index-guiding fibres, which have a solid core and guide the light through a total internal reflection, like conventional fibres. The second category corresponds to hollow-core PCFs that transmit light basing on a photonic bandgap effect. The PCFs are characterized by such geometric parameters as the hole-to-hole spacing $(\Lambda)$, the air-hole diameter $(d)$, and the air-filling fraction $(d / \Lambda)$. By manipulating one or more of these parameters, the PCFs can be designed for different applications in the fields of optical communications [5], nonlinear optics [6], sensing [7], high-power technologies [8] and telecommunications.

Among the PCFs, large mode area (LMA) fibres are now being extensively studied. They reveal very weak optical nonlinearities [9], which would otherwise limit the performance of highpower systems. In particular, the LMA-PCFs have found their applications in the high-power signal transmission, amplifiers and lasers $[10,11]$. Large hole-to-hole spacing is one of the most known techniques used for achieving the LMA effect [12]. In 1998, Knight et al. [13] have suggested a kind of LMA-PCFs with small air holes and large cores. Gates et al. [14] have studied the propagation of modes in the LMA-based holey fibres. Abdelaziz et al. [15] have designed new 
PCF structures, which consist of five air-holes rings, where the air-hole diameters differ from one ring to another. The others LMA structures are also known from the literature (see Refs. [16, 17]).

In the present work we suggest a new photonic structure where the effective mode area is further increased and the confinement loss reduced. Our PCF design is based upon six air-hole rings with two different structures and unequal diameters. In the inner structure, three air-hole rings are arranged in a hexagonal lattice, where the first ring and a number of air holes in the second and third rings are removed. Furthermore, six air holes of the third ring are filled with doped silica having high refractive index. In the outer structure, three air-hole rings are arranged in a square lattice. The cross section of our PCF has been modelled using COMSOL Multiphysics software and a known finite-element method. The simulation results testify that the effective mode area of the fundamental mode can be improved notably by applying a selective material-filled technology, with the nonlinearity and the confinement loss remaining at acceptable levels. Finally, the influence of the air-hole diameter and the index of filling material have been analyzed numerically.

\section{Theoretical approach}

In the frame of finite-element method, the cross section of PCF is divided into homogeneous subspaces for which the Maxwell's equations can be solved by accounting for adjacent subspaces. In general, the finite-element method represents a numerical technique for finding the approximate solutions of both partial differential and integral equations. The method approximates any partial differential equation as a system of ordinary differential equations which can be solved separately with different numerical techniques. Using the approach of anisotropic, perfectly matched layer, the following vectorial equation is obtained from the Maxwell's curl equations $[18,19]$ :

$$
\nabla\left(s^{-1} \nabla \times E\right)-k_{0}^{2} n^{2} s E=0 .
$$

Here $s$ denotes the matrix of the perfectly matched layer, $s^{-1}$ the inverse matrix of $s, k_{0}=2 \pi / \lambda$ the wave number in the vacuum, $\lambda$ the light wavelength, and $n$ the refractive index of the medium.

The effective mode area of the PCF is a quantitative measure for the area that a waveguide or fibre mode effectively covers along the transverse dimensions. It depends on both the core size and the doping levels that determine how tightly the mode is confined in the core. The effective mode area is calculated as follows [20,21]:

$$
A_{e f f}=\frac{\left(\iint|E|^{2} d x d y\right)^{2}}{\iint|E|^{4} d x d y},
$$

where $\mathrm{E}$ is the amplitude of the transverse electric field propagating inside the fibre.

The nonlinearity of the PCF can be measured using the nonlinear coefficient $\gamma$. The PCFs can have high nonlinearities owing to their ability of confining high-intensity light [22]. The nonlinear coefficient of the PCF can be calculated as [6]

$$
\gamma=2 \pi n^{2} / \lambda A_{e f f},
$$

where $n_{2}$ denotes the nonlinear refractive index of silica.

The confinement loss of the PCF implies the leakage of optical power from core to cladding. It is deduced from the imaginary part of the effective modal index found with simulations. This parameter is calculated as follows [23]:

$$
L_{c}=8.686 k_{0} \operatorname{Im}\left(n_{e f f}\right),
$$

where $\operatorname{Im}\left(n_{\text {eff }}\right)$ stands for the imaginary part of the effective refractive index. 


\section{Design of the fibre}

The cross section of our PCF structure is shown in Fig. 1. It is composed of six air-hole rings with two different structures, so that the air-hole diameters differ for different structures. In the inner structure of the PCF, three air-hole rings are arranged in a hexagonal lattice. Here the first ring and a number of the air holes in the second and third rings are removed. Moreover, six air holes of the third ring are filled with a high refractive-index material. In the outer structure, three air-hole rings are arranged in a square lattice.

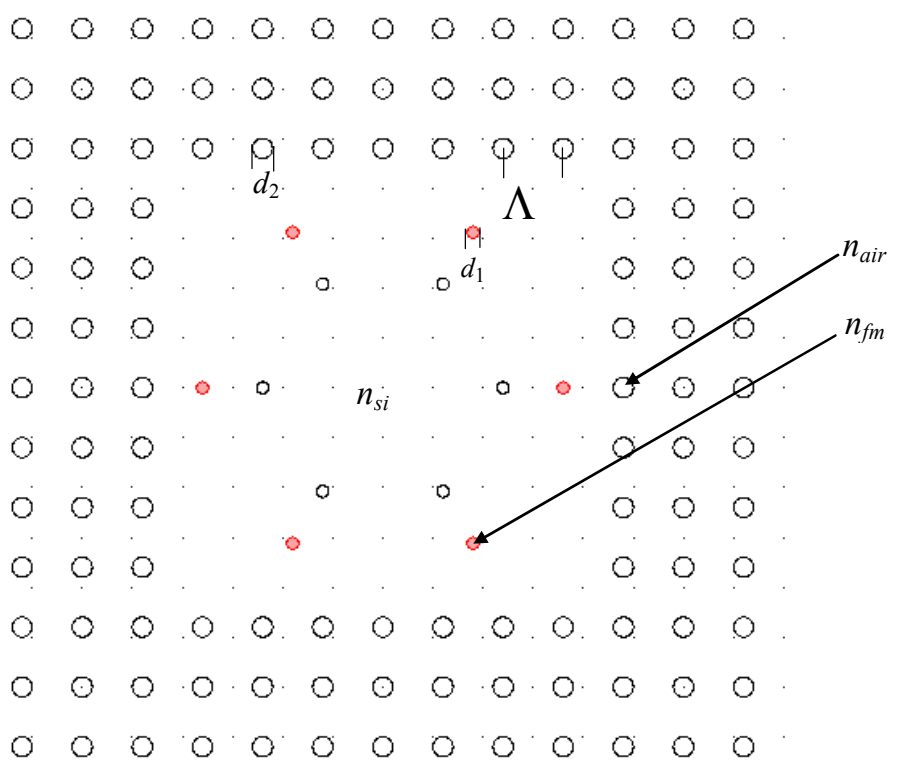

Fig. 1. Geometry of our solid-core photonic crystal fibre.

The diameter of holes in the inner structure is chosen as $d_{1}=2 \mu \mathrm{m}$, whereas the pitch that represents the distance between the two adjacent air holes is set to be $\Lambda=12 \mu \mathrm{m}$. Finally, the refraction index of the air holes $\left(\mathrm{n}_{\text {air }}\right)$ and the high refraction index $\left(n_{\mathrm{fm}}\right)$ are taken to equal respectively to 1 and 1.4507 . In the outer PCF structure, we choose the diameter $d_{2}=4 \mu \mathrm{m}$, while the pitch $\Lambda$ remains the same. The material is pure silica, of which refraction index is $n_{\mathrm{si}}=1.45$.

\section{Results and discussion}

Below, we analyze different parameters of our PCF such as the effective index, the effective mode area, the nonlinearity and the confinement loss, using the finite element method. At first, we vary the diameter of the third inner ring (which corresponds to doped holes), keeping the pitch $\Lambda$, the diameter of the second ring and the filling-material index constant. The diameters of the doped holes taken in our numerical experiments are $d_{1}=2.0,2.2$ and $2.4 \mu \mathrm{m}$ (with $d_{2}, \Lambda, n_{\mathrm{fm}}$ being equal to $4 \mu \mathrm{m}, 12 \mu \mathrm{m}$ and 1.4507 , respectively). Note that the diameter of the second ring is kept constant $(2 \mu \mathrm{m})$. One can see from Fig. 2 that the effective index decreases with increasing light wavelength and decreasing doped-hole diameter. This is due to the fact that the mode is less confined in the core at longer wavelengths, thus reducing its effective index [17]. Besides, the increase in the doped-hole diameter and the silica content in our PCF leads to increasing effective refractive index [24].

Dependences of the effective mode area on the wavelength and the doped-hole diameter are shown in Fig. 3. The effective area decreases with increasing wavelength and decreasing doped- 
hole diameter. This can be linked to the doped holes in the third ring in cladding. When higherindex materials are employed for the cladding, the propagation mode penetrates the PCF cladding deeper [17]. The same occurs with increasing doped-hole diameter and, hence, the effective mode area increases under this condition.

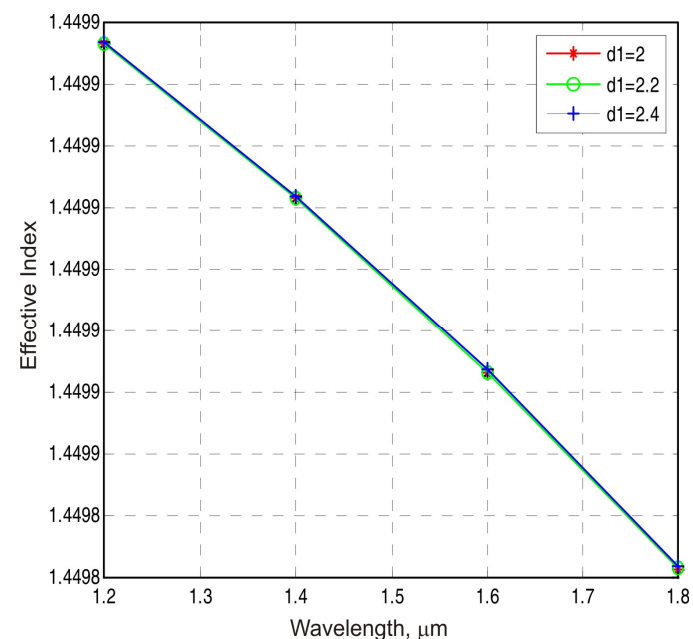

Fig. 2. Dependences of effective index on the wavelength.

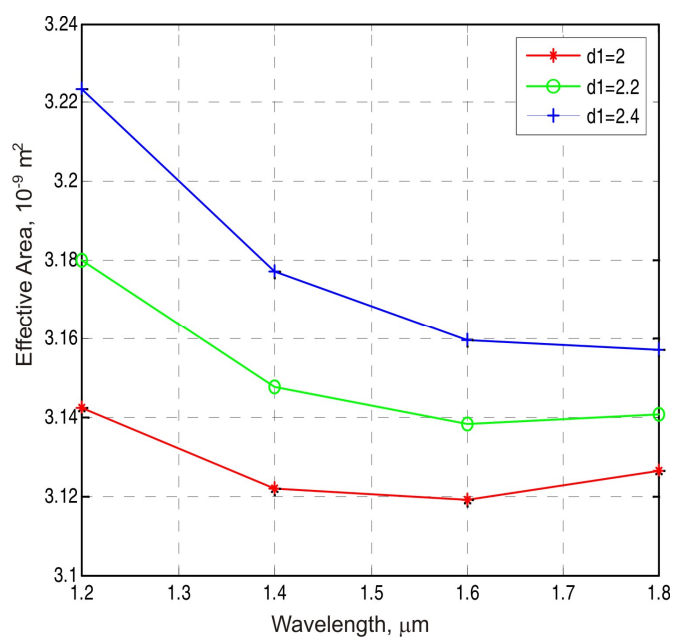

Fig. 3. Dependences of effective mode area on the wavelength.

The nonlinear coefficient as a function of light wavelength is shown in Fig. 4 at different doped-hole diameters. The nonlinearity decreases with increasing wavelength and doped-hole diameter. This is because the mode is well confined in the core at shorter wavelengths. This means that the light energy is concentrated in a small area, resulting in increasing nonlinearity [25].

In Fig. 5 we present the confinement loss as a function of wavelength, as calculated at three different doped-hole diameters. The confinement loss increases with increasing doped-hole diameter. As mentioned above, the increase in the doped-hole diameter leads to increasing effective mode area, so that the confinement loss also increases. The increase in the confinement loss occurring at longer wavelengths is caused by that fact that the light starts to penetrate deeper and deeper into the cladding.

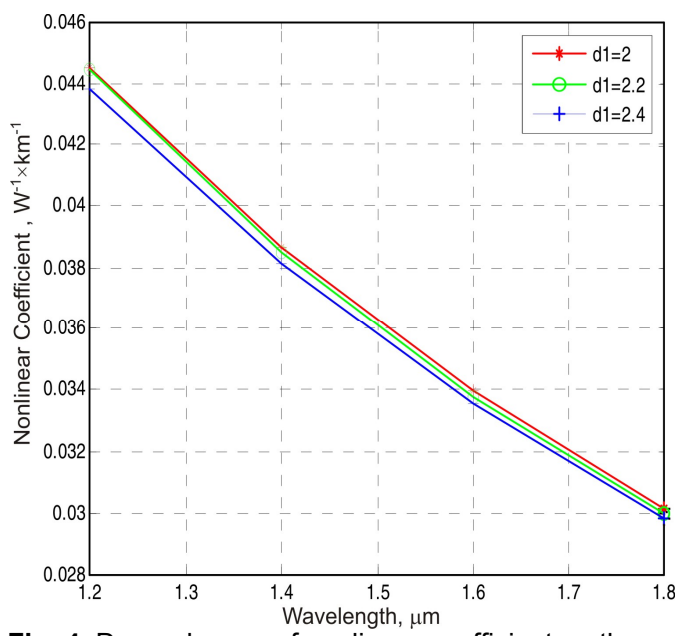

Fig. 4. Dependences of nonlinear coefficient on the wavelength.

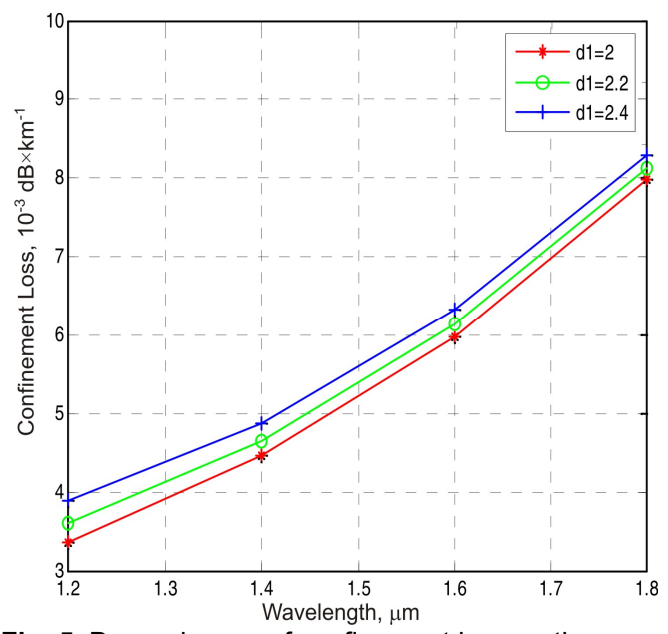

Fig. 5. Dependences of confinement loss on the wavelength. 
In our further model calculations, the refractive index of the filling material has been varied, while keeping constant the inner-hole diameter $\left(d_{1}=2 \mu \mathrm{m}\right)$ and the pitch $(\Lambda=12 \mu \mathrm{m})$. The index values for the filling material taken in this study have been equal to $1.4507,1.4515$ and 1.452 . It is seen from Fig. 6 that the effective index decreases with increasing wavelength and decreasing index of the filling material. This is in accordance with the fact that, at longer wavelengths, the mode is less confined in the core. Then the effective-index decrease follows.

The effective mode area as a function of light wavelength is presented in Fig. 7 for different indices of the filling material. It is obvious that the effective area decreases with increasing wavelength and decreasing index of the filling material. This behaviour can be explained by the fact that the propagation mode penetrates deeper into the PCF cladding.

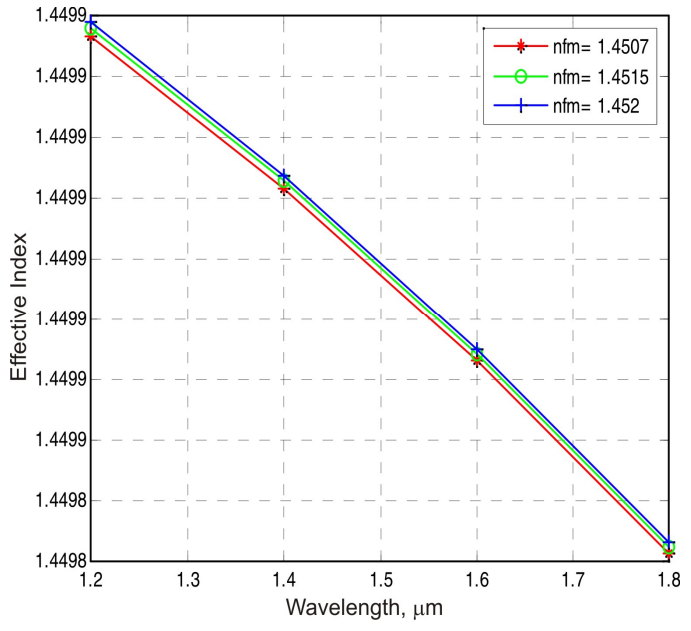

Fig. 6. Dependences of effective mode index on the wavelength.

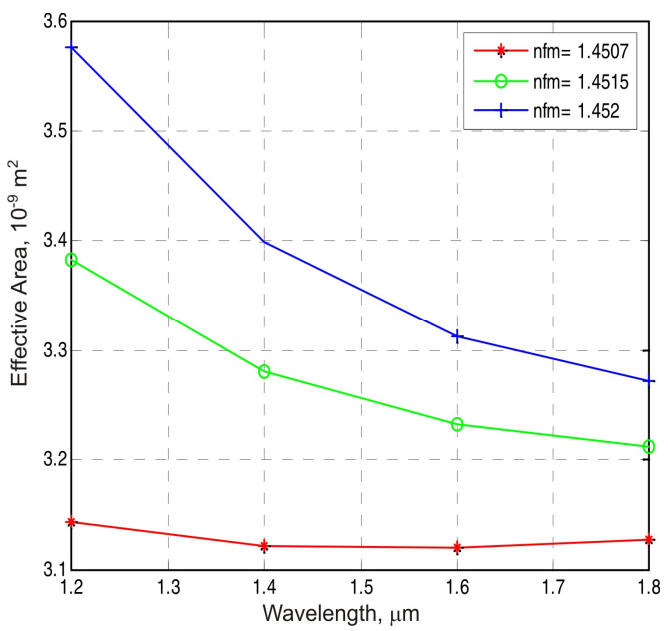

Fig. 7. Dependences of effective mode area on the wavelength.

It can be seen from Fig. 8 that the nonlinearity decreases with increasing light wavelength and increases with decreasing filling-material index. As expected (see Ref. [26]), the optical energy is concentrated in a smaller area at shorter wavelengths, so that the nonlinearity increases. Moreover, increase in the filling-material index leads to increasing effective mode area. As a consequence, the nonlinear coefficient decreases under this condition.

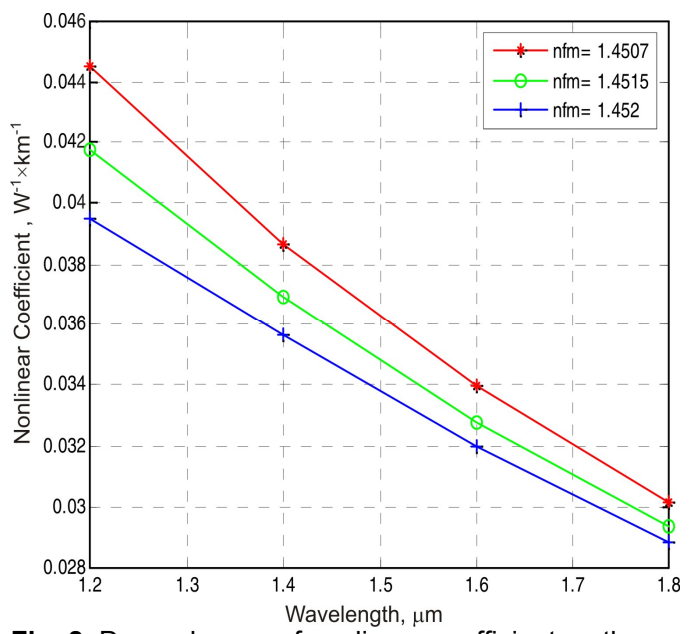

Fig. 8. Dependences of nonlinear coefficient on the wavelength.

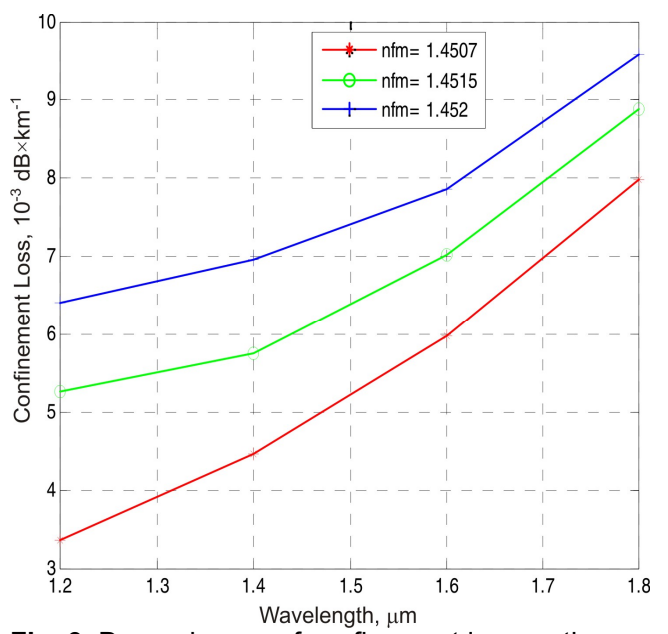

Fig. 9. Dependences of confinement loss on the wavelength.

Ukr. J. Phys. Opt. 2019, Volume 20, Issue 2 
Finally, Fig. 9 displays the confinement loss as a function of light wavelength, as calculated at different values of the filling-material index. The loss increases with increasing wavelength and filling-material index. As already mentioned, the light starts to leak further into the cladding at longer wavelengths, thus causing an increase in the confinement loss.

\section{Conclusion}

We suggest a new design for the PCF in order to improve its transmission characteristics such as the effective mode area, the nonlinearity and the confinement loss. We achieve a large effective mode area (about $3575 \mu \mathrm{m}^{2}$ at $1.2 \mu \mathrm{m}$ ), a low nonlinear coefficient $\left(\sim 3.25 \times 10^{-2} \mathrm{~W}^{-1} \mathrm{~km}^{-1)}\right.$ and low confinement losses $\left(\sim 5.70 \times 10^{-3} \mathrm{~dB} / \mathrm{km}\right.$ at $\left.1.55 \mu \mathrm{m}\right)$. These results are derived with the modelling based on the COMSOL Multiphysics software and the finite-element method. The fibre suggested in the present work can be used for optical communication and high-power signal transmission, as well as in optical amplifiers and lasers.

\section{References}

1. Birks T A, Knight J C and Russell P S, 1997. Endlessly single mode photonic crystal fiber. Opt. Lett. 22: 961-963.

2. Knight J C, Arriaga J, Birks T A, Ortigosa-Blanch A, Wadsworth W J and Russell P St J, 2000. Anomalous dispersion in photonic crystal fiber. IEEE Photon. Technol. Lett. 12: 807809.

3. Broderick N G R, Monro T M, Bennett P J and Richardson D J, 1999. Nonlinearity in holey optical fibers: measurement and future opportunities. Opt. Lett. 24: 1395-1397.

4. Russell P S, 2006. Photonic-crystal fibers. J. Lightwave Technol. 24: 4729-4749.

5. Hansryd J, Andrekson P A, Westlund M, Li J and Hedekvist P O, 2002. Fiber-based optical parametric amplifiers and their applications. IEEE J. Select. Topics Quant. Electron. 8: 506520 .

6. Agrawal G P, Nonlinear fiber optics. $4^{\text {th }}$ Ed. San Diego: Academic (2006).

7. Belhadj W, AbdelMalek F and Bouchriha H, 2006. Characterization and study of photonic crystal fibres with bends. Mater. Sci. Eng. 26: 578-579.

8. Limpert J, Schreiber T, Nolte S, Zellmer H, Tunnermann T, Iliew R, Lederer F, Broeng J, Vienne G, Petersson A, and Jakobsen C, 2003. Highpower air-clad large-mode-area photonic crystal fiber laser. Opt. Express. 11: 818-823.

9. Zolla F, Renversez G, Nicolet A, Kuhlmey B, Guenneau S, and Felbacq D. Foundations of photonic crystal fibres. London: Imperial College Press (2005).

10. Slusher R E and Eggleton B J, Nonlinear photonic crystals. Berlin: Springer Verlag (2003).

11. Wadsworth W, Percival R, Bouwmans G, Knight J and Russell P S, 2003. High power airclad photonic crystal fibre laser. Opt. Express. 11: 48-53.

12. Ritari T, Niemi T, Wegmuller M, Gisin N, Folkenberg J R, Pettersson A and Ludvigsen H, 2003. Polarization-mode dispersion of large mode-area photonic crystal fibers. J. Opt. Commun. 226: 233-239.

13. Knight J C, Birks T A, Cregan R F, Russell P S and Sandro J P, 1998. Large mode area photonic crystal fibre. Electron. Lett. 34: 1347 - 1348.

14. Gates J C, Hillman C W J, Baggett J C, Furusawa K, Monro T M and Brocklesby W S, 2004 Structure and propagation of modes of large mode area holey fibers. Opt. Express. 12: 847852 . 
15. Abdelaziz I, AbdelMalek F, Ademgil H, Haxha S, Gorman T and Bouchriha H, 2010. Enhanced effective area photonic crystal fiber with novel air hole design. J. Lightwave Technol. 28: 2810-2817.

16. Rostami A and Soofi H, 2011. Correspondence between effective mode area and dispersion variations in defected core photonic crystal fibers. J. Lightwave Technol. 29: 234-241.

17. Haxha $\mathrm{S}$ and Ademgil H, 2008. Novel design of photonic crystal fibres with low confinement losses, nearly zero ultra-flatted chromatic dispersion, negative chromatic dispersion and improved effective mode area. Opt. Commun. 281: 278-286.

18. Ademgil $\mathrm{H}$ and Haxha S, 2008. Highly birefringent photonic crystal fibers with ultralow chromatic dispersion and low confinement losses. IEEE J. Lightwave Technol. 26: 441-448.

19. Selleri S, Vincetti L, Cucinotta A and Zoboli M, 2001. Complex FEM modal solver of optical waveguides with PML boundary conditions. Opt. Quant. Electron. 33: 359-371.

20. Pourmahyabadi $\mathrm{M}$ and Sh Mohammad Nejad, 2009. Numerical analysis of index-guiding photonic crystal fibers with low confinement loss and ultra-flattened dispersion by FDFD method. Iran. J. Electr. \& Electron. Eng. 5: 170-179.

21. Mortensen NA, 2002. Effective area of photonic crystal fibers. Opt. Express. 10: 341-348.

22. Koshiba M and Tsuji Y, 2000. Curvilinear hybrid edge/nodal elements with triangular shape for guided-wave problems. J. Lightwave Technol. 18: 737-743.

23. Mishra S S and Vinod K, 2011. Singh highly birefringent photonic crystal fiber with low confinement loss at wavelength $1.55 \mu \mathrm{m}$. Optik. 122: 1975-1977.

24. Hameed M F O and Obayya S S A, 2012. Modal analysis of a novel soft glass photonic crystal fiber with liquid crystal core. J. Lightwave Technol. 30: 96-102.

25. Mishra S S and Singh V K, 2011. Study of non-linear properties of hollow core photonic crystal fiber. Optik. 122: 687-690.

26. Benhaddad M, Kerrour F and Benabbes O, 2018. Design and analysis of non-linear properties of photonic crystal fiber with various doping concentration. J. Phys.: Conf. Ser. 987: 012010.

Benhaddad M., Kerrour F., Benabbes O. and Saouli A. 2019. A new photonic crystal fibre with low nonlinearity, low confinement loss and improved effective mode area. Ukr.J.Phys.Opt. 20: 47 - 53. doi: 10.3116/16091833/20/2/47/2019

Анотація. Для усунення недоліків звичайних волокон, пов'язаних з нелінійними ефектами, широко використовують волокна на фотонних кристалах із великою «площеюю моди». Ми представлясмо нову конструкиію волокон на фотонних кристалах з великою ефективною «площеюю моди». Волокно складається з шести наповнених повітрям кілець з двома різними структурами $і$ різними діаметрами, де повітряні отвори третього кільия заповнені речовиною, щзо має високий показник заломлення. На основі повного векторного методу скінченних елементів ми з'ясували, що така структура виявляє значну ефективну «плошу моди» (до 3575 мкм ${ }^{2}$ на довжині хвилі світла 1200 нм), а також низькі втрати

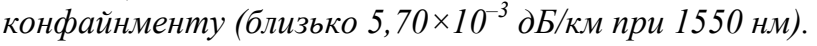

